\title{
The Effects of Lewis Acid Complexation on Type I Radical Photoinitiators and Implications for Pulsed Laser Polymerization
}

\author{
Benjamin. B. Noble, Adam. C. Mater, Leesa M. Smith and Michelle. L. Coote*
}

In the present work, we examine the effects of zinc chloride $\left(\mathrm{ZnCl}_{2}\right)$ and aluminium chloride $\left(\mathrm{AlCl}_{3}\right)$ complexation on the photochemistry of two well-known Type I photoinitiators, methyl-4'-(methylthio)-2-morpholinopropiophenone (MMMP) and 2,2-dimethoxy-2-phenylacetophenone (DMPA). High-level ab initio calculations and experimental results demonstrate that Lewis acid complexation has a significant effect on the individual processes that comprise radical photoinitiation. Theoretical calculations predict that $\mathrm{ZnCl}_{2}$ coordinates to MMMP and DMPA to form thermodynamically stable bidentate ketone-amine and ketone-ether chelates, respectively. Meanwhile, the $\mathrm{AlCl}_{2}{ }^{+}$cation coordinates to MMMP and DMPA to form a tridentate ether-amine-ketone chelate and a bidentate ketone-ether chelate, respectively. We found that addition of $\mathrm{ZnCl}_{2}$ and $\mathrm{AlCl}_{3}$ to solutions containing MMMP significantly increase its molar extinction coefficient $(\varepsilon)$ between $350-360 \mathrm{~nm}$. In contrast, the complexation of either $\mathrm{ZnCl}_{2}$ or $\mathrm{AlCl}_{3}$ to $\mathrm{DMPA}$ slightly reduces the value of $\varepsilon$ in the $350-$ $360 \mathrm{~nm}$ range. Time dependent density functional theory (TD-DFT) calculations demonstrate that Lewis acid complexation blue shifts the $\mathrm{n} \pi$ excitations of both DMPA and MMMP, while concurrently red shifting the $\pi \pi^{*}$ transitions. Complexation also significantly alters the stability and reactivity of the photoinitiator fragment radicals. Lewis acid complexation localizes and destabilizes acyl radicals, resulting in significantly increased reactivity towards methyl methacrylate (MMA). In contrast, complexation of Lewis acids dramatically reduces the reactivity of the morpholine substituted isopropyl radical and the dimethoxyphenyl radical towards MMA. Alternative complexation at the methyl ester side-chain of MMA has a beneficial effect on the reactivity of all fragments, increasing addition rate coefficients by 2-4 orders of magnitude. We discuss some of the important implications of these findings for pulsed laser polymerization (PLP), and acetophenone photochemistry more generally.

\section{Introduction}

Pulsed laser polymerization (PLP) is an elegant kinetic technique that allows propagation rate coefficients $\left(k_{\mathrm{p}}\right)$ to be determined with very high accuracy and precision. ${ }^{1-3}$ In a PLP experiment, consecutive laser pulses are used to generate radicals at regular intervals via the photolysis of a photoinitiator. These fragment radicals rapidly initiate polymer chain-growth, which continues until they are terminated by analogous fragments generated from subsequent laser pulses. Some of the growing polymer chains will not be terminated by the immediately following laser pulse but will continue to propagate until subsequent pulses. This leads to a characteristic multimodal molecular weight distribution (MWD), which can be analysed by size-exclusion chromatography (SEC) to determine $k_{\mathrm{p}}$ in a relatively modelfree manner.

While PLP is a reasonably robust method for $k_{\mathrm{p}}$ determination, it requires fairly specific radical fluxes; otherwise the resultant MWD will be devoid of the features necessary for accurate $k_{\mathrm{p}}$ determination. ${ }^{4}$ If the radical flux generated by each laser pulse is too small, the termination of propagating polymer chains will not be properly controlled by the laser pulses; the so called "low-termination limit". Under

\footnotetext{
* ARC Centre of Excellence for Electromaterials Science, Research School of Chemistry, Australian National University, Canberra ACT 2601, Australia michelle.coote@anu.edu.au

Electronic Supplementary Information (ESI) available: A more detailed description of all the computational procedures, conformational searching, benchmarking and a full set of obtained results for all the species in this work. See DOI: $10.1039 / x 0 x x 00000 x$
}

low-termination limit conditions, the MWD can contain artefacts caused by irregular (non-laser controlled) termination and erroneous dependencies of $k_{\mathrm{p}}$ on laser pulsing-rate can be observed. ${ }^{5}$ Moreover, MWDs obtained under low-termination limit conditions often have several poorly resolved inflection points that may not be integer multiples of the apparent primary peak; with the true primary peak being obscured. Conversely, if the radical flux generated on each laser pulse is too large, then almost all the propagating polymer chains will be terminated after every pulse and the so called "high-termination limit" is reached. Under high-termination limit conditions, formation of the secondary (and any higher order) molecular weight peaks (or 'overtones') will be suppressed and a featureless MWD that is composed entirely of the primary peak material will be obtained.

The radical flux in a given PLP experiment will be determined by several factors, including the laser pulse energy, as well as the photoinitiator identity and concentration. However, because of photoinitiator consumption, a broad range of radical concentrations may be sampled in a single experiment. ${ }^{6}$ Thus, obtaining a MWD with PLP characteristics depends on the appropriate selection of total irradiation time, laser power, pulse-rate and the photoinitiator identity as well as its initial concentration. The conditions necessary for PLP are well established for most common monomers, notably: acrylates, ${ }^{7,} 8$ methacrylates, ${ }^{9-11}$ styrene $^{12}$ and acrylamide. ${ }^{13}$

As illustrated schematically in Fig. 1, acetophenone photoinitiation is itself a highly complex phenomenon that is comprised of various individual processes. First, the photoinitiator absorbs incident light; with a given molar 
extinction coefficient $(\varepsilon)$ describing the portion of photons that are absorbed at a particular wavelength. Depending on the wavelength(s) emitted by the light source and the energy of the singlet excited states, excitations to several excited states may occur (for instance $S_{1}$ and $S_{2}$ in Fig. 1). Internal conversions (IC) can then lead to very rapid de-excitation between excited states of similar energies, without photon emission (with compensating vibrational and rotational excitations). A given singlet excited state $\left(S_{1}\right.$ in Fig. 1 ) will then undergo an ultra-fast inter-system crossing (ISC) to a triplet state of comparable energy (with an efficiency given by $\varphi_{\text {isc }}$ ). From a triplet state $\left(T_{1}\right.$ in Fig. 1$)$ the photoinitiator can fragment via $\alpha$-cleavage to form two radical species (with a rate coefficient $k_{\mathrm{c}}$ and lifetime $\tau_{\mathrm{T} 1}$ ). These radical fragments react with monomer to initiate (radical) polymerization with a particular rate coefficient $\left(k_{\text {add }}\right)$.

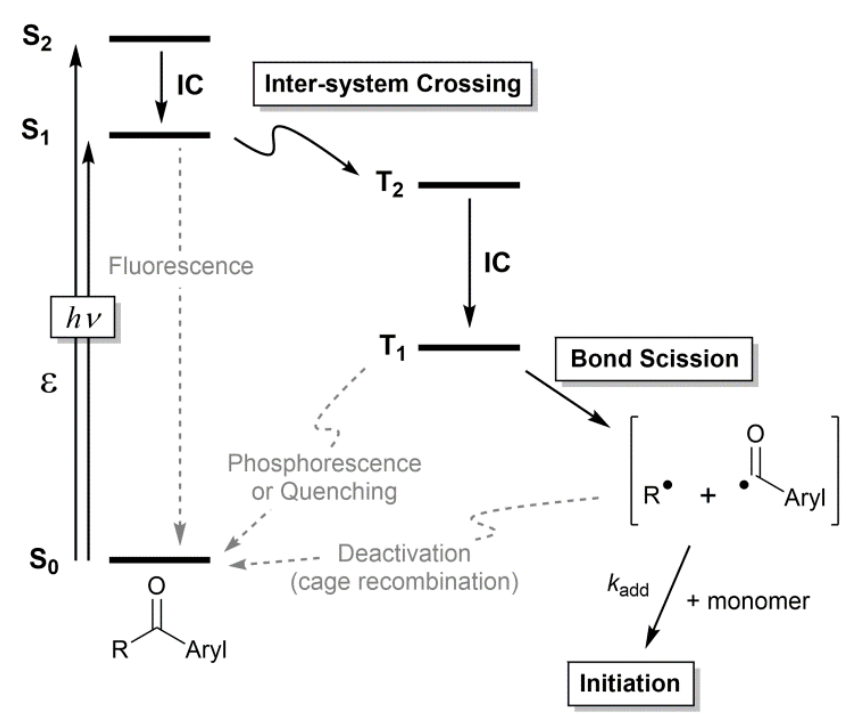

Fig. 1 a Jablonski diagram illustrating the photoinitiation of a type I acetophenone initiator. Note that vibrational relaxation is omitted for clarity.

Several competing processes (marked in grey in Fig. 1) can reduce the efficiency of photoinitiation, although most of these side-processes simply reform ground-state photoinitiator. For instance, following the absorption of incident light, fluorescence can lead to de-excitation with a compensating radiative emission. Hence, the efficiency of photoinitiation will partly depend on the relative rates of ISC and fluorescence. Similarly, following an ISC to the triplet manifold, radical generation will be in competition with phosphorescence and de-excitation via photoquenching (rate coefficient, $k_{\mathrm{q}}$ ). Even after bond scission, the fragment radicals can recouple inside their solvent cage to regenerate the ground state photoinitiator, instead of initiating polymer chain growth.

For a type I photoinitiator, the initiation quantum yield $\left(\varphi_{\mathrm{i}}\right)$ will depend on the relative efficiency of initiation compared with these side-processes. ${ }^{14}$ Initiation quantum yield can be expressed mathematically as follows ${ }^{14}$ :

$$
\varphi_{i}=\varphi_{i s c}\left(\frac{k_{c}}{\frac{1}{\tau_{T 1}}+k_{q}[M]}\right)\left(\frac{k_{a d d}[M]}{k_{r}^{0}+k_{a d d}[M]}\right)
$$

Where $k_{r}{ }^{0}$ is the sum of pseudo first-order rate coefficients for the decay of the formed radical and $[\mathrm{M}]$ is the monomer concentration. Meanwhile, under steady state conditions, initiation quantum yield is related to the overall polymerization rate $\left(R_{p}\right)$ as follows ${ }^{14}$ :

$$
R_{p}=\frac{k_{p}[M]}{\sqrt{k_{t}}} \sqrt{\varphi_{i} I_{0}(1-\exp (-2.3 \varepsilon l[I])}
$$

Where $k_{t}$ is the termination rate coefficient, $\mathrm{I}_{0}$ is the energy of the incident light, $I$ is the path-length and [I] is the photoinitiator concentration.

Our interest in photoinitiation was prompted by our attempts to use PLP to quantify the catalytic effects of Lewis acids on propagation kinetics. We recently successfully employed PLP to show that the weak Lewis acid lithium bis(trifluromethane)sulfonamide $\left(\right.$ LiNTf $\left._{2}\right)$ catalyses the propagation of methyl methacrylate (MMA). ${ }^{15}$ Earlier work by Pedron and co-workers also used PLP to explore the effect of lithium triflate (LiOTf) on the propagation kinetics of ethoxy methacrylates, noting similar catalytic effects. ${ }^{16}$ However, LiNTf $_{2}$ and LiOTf are relatively weak Lewis acids and our attempts to examine the effects of stronger Lewis acids were hampered by the loss of PLP characteristics, especially at higher flashing rates. This was despite the fact that the same reaction conditions produced excellent PLP characteristics in the absence of these Lewis acids. More generally we note that PLP kinetic studies of Lewis acid-mediated radical polymerization are rare, although encouraging $k_{\mathrm{p}}$ enhancement has been observed in ionic liquids. ${ }^{17-23}$

While the deterioration of PLP characteristics suggests that Lewis acids may adversely affect radical photoinitiation, the precise impacts of complexation are poorly understood. Without proper understanding of these effects, it is difficult to determine which photoinitiator/ Lewis acid combinations might be particularly susceptible. Given its complexity, properly predicting (or rationalizing) initiator efficiency requires the simultaneous evaluation of multiple factors. ${ }^{24}$ Assessments to correlate efficiency to a single property, such as $\varepsilon$ values, will generally lead to erroneous conclusions. An array of different experimental techniques (often employed in tandem) can be used to study photoinitiation, including IRbased techniques, fluorescence probes, ${ }^{25}$ steady-state photolysis, ${ }^{26,27}$ photodifferential scanning calorimetry, ${ }^{28}$, EPRbased methods, 26, 27, 29 laser flash photolysis 30,31 and electrospray ionization mass spectrometry. ${ }^{24}$, 32, 33 While various experimental approaches can be used to study the performance of different photoinitiators, it is likely that the presence of Lewis acids would also affect $k_{\mathrm{p}}$ and $k_{\mathrm{t}}$. Hence, initiator efficiencies may not be straightforwardly related to conversions, molecular weights or transient radical concentrations. 
In this context, we have carried out a combined experimental and theoretical study to assess the impacts of Lewis acid coordination on the individual factors that collectively determine photoinitiator efficiency. In this work, we examine the effects of two important Lewis acids, zinc chloride $\left(\mathrm{ZnCl}_{2}\right)$ and aluminium chloride $\left(\mathrm{AlCl}_{3}\right)$, on two popular Type I acetophenone photoinitiators; methyl-4'-(methylthio)2-morpholinopropiophenone (MMMP) and 2,2-dimethoxy-2phenylacetophenone (DMPA) (see Fig. 2). We then examine the behaviour of these systems, highlighting the diverse, and at times divergent, effects Lewis acids can have on photolysis and fragment reactivity. The implications of these results for successful PLP in the presence of Lewis acids are then discussed.
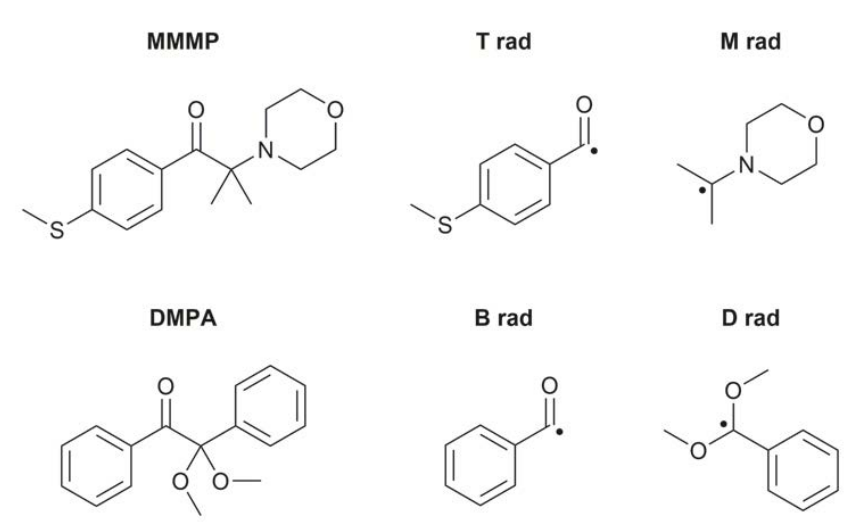

Fig. 2 Chemical structures of MMMP and DMPA and the fragment radicals that result from photolysis.

\section{Materials}

Ethyl acetate (EA) (Emsure, > 99.5\%) was first dried over anhydrous magnesium sulfate (Emsure, $>98 \%$ ) and then on activated $3 \AA$ molecular sieves (Aldrich). 2-methyl-4'(methylthio)-2-morpholinopropiophenone (MMMP) (Aldrich, $98 \%)$ was purified by recrystallization in ethanol prior to use. 2,2-dimethoxy-2-phenylacetophenone (DMPA) (Aldrich, 99\%) was purified by recrystallization in ethanol/ water and dried under vacuum at room temperature. Zinc chloride (Aldrich, > 99.995\%) and aluminium chloride (Aldrich, > 99.99\%) were used as received.

\section{Experimental}

UV spectra were measured on a Cary-Bio 50 spectrophotometer in quartz cells with $1 \mathrm{~cm}$ path length. We verified that neat ethyl acetate (EA) has no significant absorptions in the $260-380 \mathrm{~nm}$ range (see Fig. S1 in ESI). Moreover, we confirmed that in the absence of MMMP and DMPA, solutions of $\mathrm{ZnCl}_{2}$ and $\mathrm{AlCl}_{3}$ in $\mathrm{EA}$ are similarly transparent in this range (see Fig. S1 ESI). Thus, we note that the observed changes in UV spectra following Lewis acid addition cannot be attributed to charge transfer absorbance between the Lewis acids and EA solvent, or to trace impurities that may be present in either Lewis acid. Manipulations involving $\mathrm{ZnCl}_{2}$ and $\mathrm{AlCl}_{3}$ (and their respective EA solutions) were performed under an $\mathrm{N}_{2}$ atmosphere using standard dry box techniques. Spectra were taken immediately in sealed quartz cells to prevent contamination from atmospheric moisture that could potentially react with the Lewis acids.

\section{Theoretical Methodology}

All geometry optimizations were performed using the M06-2X functional, 34 in combination with a modified $6-31+G(d, p)$ basis set. This modified basis set utilizes the standard $6-31+G(d, p)$ basis set for atoms first and second row atoms, ${ }^{35-39}$ in conjunction with the all electron $6-31 \mathrm{G}(\mathrm{d})$ basis set for $\mathrm{Zn} .{ }^{40}$ Entropies, thermal corrections and zero-point vibrational energies were scaled by recommend scale factors. ${ }^{41}$ Improved single-point energies were calculated using the high-level composite $a b$ initio G3(MP2)-RAD method, ${ }^{42}$ in conjunction with the ONIOM approximation ${ }^{43}, 44$ for larger systems. The SMD solvent model ${ }^{45}$ was used to correct for implicit solvent effects. The methodology used in this work has been extensively benchmarked, including for radical addition kinetics and bond homolysis. ${ }^{46-48}$ Moreover, in the present work, we benchmarked this methodology against experimentally available Lewis acid/ base binding enthalpies and rate coefficients for similar radical addition reactions (see Table S2 and S3 as well as Fig. S2 and S3 of ESI).

Adiabatic ionization energies (IE) of the radical fragments and electron affinities (EA) of monomer species where calculated using G3(MP2)-RAD(+); a modified version of G3(MP2)-RAD where single point energy calculations are performed with the $6-31+G(d)$ basis set instead of $6-31 G(d)$ for better treatment of anionic species. Time dependent density functional theory (TD-DFT) was performed with M06-2X and the modified $6-31+G(d, p)$ basis set, in conjunction with the SMD solvent model. ${ }^{45}$ Electrostatic potential surfaces (ESPs) are based on Gasteiger point charges calculated using the UM06-2X/6-31+G(d,p) SCF density. All standard $a b$ initio molecular orbital theory, density functional theory (DFT) and time dependent-density functional theory (TD-DFT) calculations were carried out using Gaussian $09^{49}$ as well as Molpro $2012^{50}$ and $2015^{50}$ software packages. A more detailed description of all the computational procedures, conformational searching, benchmarking and a full set of obtained results can be found in the Electronic Supplementary Information.

\section{Results and Discussion}

As overall initiator efficiency is dependent on several different factors, we have utilized a combination of experimental and theoretical techniques to better understand the effects of Lewis acid complexation on each aspect of photoinitiation. Results of this comprehensive investigation are now presented and discussed in turn.

\section{Lewis acid binding modes to MMMP and DMPA}


Prior to assessing the impact of $\mathrm{AlCl}_{3}$ and $\mathrm{ZnCl}_{2}$ on the photoexcitation behaviour of MMMP and DMPA, the precise coordination structure of all relevant complexes and their stability must be determined. MMMP and DMPA contain multiple Lewis base-donor sites and so can coordinate $\mathrm{AlCl}_{3}$ and $\mathrm{ZnCl}_{2}$ in several different binding arrangements, many of which have multiple conformational isomers. We rigorously examined each of these possible binding modes to determine the most energetically favourable complex for each Lewis acid/ photoinitiator combination. In addition to evaluating the mode of complexation, we also determined the thermodynamic selectivity for photoinitiator complexation in the presence of competing solvation of the Lewis acid by MMA monomer. To ensure that the theoretical methodology used could accurately describe Lewis acid/ base interactions, we benchmarked it using experimentally obtained binding enthalpies for an array of boron trifluoride $\left(\mathrm{BF}_{3}\right)$ complexes with common ligands, 51 including esters, ketones, amines and ethers. Excellent quantitative agreement was noted between theoretically predicted values and reliable calorimetric data; with a mean absolute deviation and maximum deviation of 2.6 and $5.2 \mathrm{~kJ}$ $\mathrm{mol}^{-1}$, respectively (see Table S2 and Fig. S2 of ESI).

As a Lewis base, MMMP possesses 4 potential donor sites: the $\mathrm{O}$ atoms of the ketone and ether, the $\mathrm{N}$ atom of the amine and the $\mathrm{S}$ atom of the thioether. In addition to examining monodentate coordination of $\mathrm{AlCl}_{3}$ and $\mathrm{ZnCl}_{2}$ at each of these donor sites, we also exhaustively considered various possible bi- and tri-dentate coordination modes. Meanwhile, DMPA possesses 3 potential ligation sites: a ketone and two methoxy ether moieties. For both $\mathrm{AlCl}_{3}$ and $\mathrm{ZnCl}_{2}$, we investigated monodentate coordination at each donor site and also bidentate ketone-ether coordination. As $\mathrm{AlCl}_{3}$ has a known tendency to form $\left[\mathrm{AlCl}_{2}(\text { ligand })_{n}\right]\left[\mathrm{AlCl}_{4}\right]$ type complexes in solution, 52,53 coordination of the $\left[\mathrm{AlCl}_{2}\right]^{+}$cation to both photoinitiators was also considered. The geometries of the most thermodynamically favourable Lewis acid/ photoinitiator complexes and their relative binding free-energies in MMA solution are given in Fig. 3.

As Fig. 3 illustrates, the most favourable mode of $\mathrm{ZnCl}_{2}$ complexation to MMMP and DMPA is via a 5-membered ketone-amine and ketone-ether chelate, respectively. Assuming neutral complex speciation, the bulkier $\mathrm{AlCl}_{3}$ coordinates to the ether of MMMP in a monodentate arrangement, with complexation at the ketone moiety also reasonably favourable (see Fig. S4 of ESI). Meanwhile calculations predict that $\mathrm{AlCl}_{3}$ preferentially coordinates to the ketone of DMPA to form a neutral monodentate ketone complex (see Fig. S4 of ESI). However, reaction of the neutral $\left[\mathrm{AlCl}_{3}(\mathrm{MMMP})\right]$ and $\left[\mathrm{AlCl}_{3}(\mathrm{MMA})\right]$ complexes to form the $\left[\mathrm{AlCl}_{2}(\mathrm{MMMP})\right]\left[\mathrm{AlCl}_{4}\right]$ contact ion-pair was found to be quite energetically feasible $\left(-11.7 \mathrm{~kJ} \mathrm{~mol}^{-1}\right)$. Indeed, Levason and coworkers found that many $\mathrm{AlCl}_{3}$ complexes adopt analogous ion-pair type structures with bidendate diphosphine ligands. ${ }^{54}$ Moreover, even in relatively low polarity solvents, such as tetrahydrofuran (THF), the formation of $\left[\mathrm{AlCl}_{4}\right]^{-}$has been detected. ${ }^{52}$ As illustrated in Fig. 3, the cationic $\left[\mathrm{AlCl}_{2}(\mathrm{MMMP})\right]^{+}$ complex adopts a tridentate ketone-amine-ether chelate, while the $\left[\mathrm{AlCl}_{2} \text { (DMPA) }\right]^{+}$complex forms a bidentate ketoether chelate coordination structure.

We should note that the exact conditions used in PLP experiments, in particular the Lewis acid/ monomer identity and concentration, may affect the Lewis acid/ photoinitiator complex stability. Furthermore, in the case of $\mathrm{AlCl}_{3}$, the precise speciation is almost certainly quite complicated (and condition dependent). At high $\mathrm{AlCl}_{3}$ loadings, significant amounts of $\mathrm{Cl}^{-}$ abstraction and ion-pairing of the resultant species would be anticipated. Under these conditions the complexes shown in Fig. 3 would predominate, due to their high binding selectivity over the comparably solvated monomer complexes. At very low $\mathrm{AlCl}_{3}$ loadings, the dominate species present would be 
$\left[\mathrm{ZnCl}_{2}(\mathrm{MMMP})\right]: \mathbf{- 4 8 . 2}$

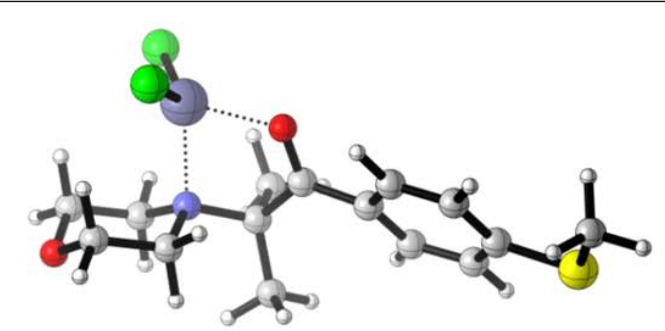

$\left[\mathrm{ZnCl}_{2}(\mathrm{DMPA})\right]:-39.0$

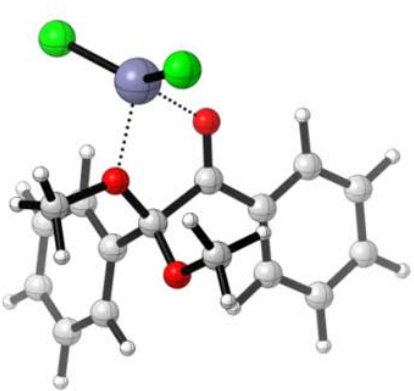

$\left[\mathrm{AICl}_{2}(\mathrm{MMMP})\right]^{+}:-34.1$

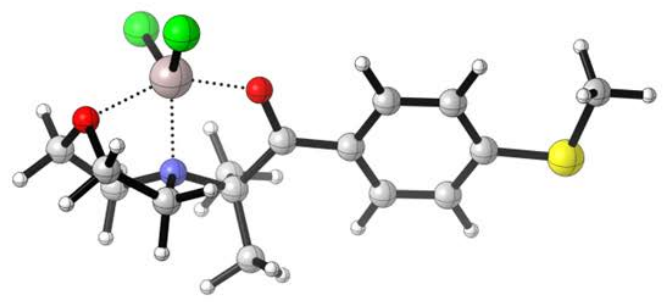

$\left[\mathrm{AICl}_{2}(\mathrm{DMPA})\right]^{+}: \mathbf{- 4 2 . 7}$

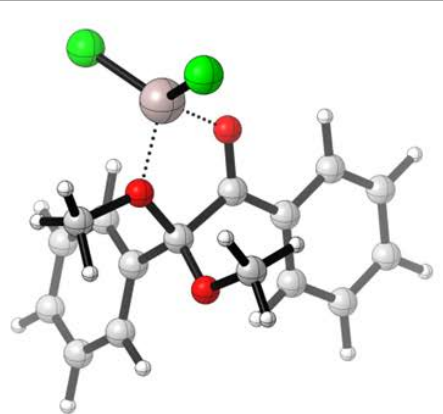

Fig. 3. Predicted coordination structures of the $\left[\mathrm{ZnCl}_{2}(\mathrm{MMMP})\right],\left[\mathrm{AlCl}_{2}(\mathrm{MMMP})\right]^{+},\left[\mathrm{ZnCl}_{2}(\mathrm{DMPA})\right]$ and $\left[\mathrm{AICl} \mathrm{Cl}_{2}(\mathrm{DMPA})\right]^{+}$complexes. Note that an addition solvating $\mathrm{MMA}$ ligand was omitted from the $\left[\mathrm{AlCl}_{2}(\mathrm{DMPA})\right]^{+}$complex for clarity. The Gibbs Free Binding Energy of each photoinitiator complex, relative to competing solvation by MMA monomer, is indicated in $\mathrm{kJ} \mathrm{mol}^{-1}$.

neutral $\left[\mathrm{AlCl}_{3}(\mathrm{MMA})\right]$, in which case the speciation predicted in Fig. S4 may be observed. We should note that the very low binding selectivity for the neutral $\left[\mathrm{AlCl}_{3}(\mathrm{MMMP})\right]$ complex is inconsistent with the observed changes in the respective UVVis spectra (see Fig. 4). Thus, we conclude that under the conditions used in a typical PLP experiment ( $>1 \mathrm{~mol} \% \mathrm{AlCl}_{3}$ loading), sufficient $\mathrm{AlCl}_{2}{ }^{+}$is available to form $\left[\mathrm{AlCl}_{2}(\mathrm{MMMP})\right]\left[\mathrm{AlCl}_{4}\right]$ and $\left[\mathrm{AlCl}_{2}(\mathrm{DMPA})\right]\left[\mathrm{AlCl}_{4}\right]$ type photoinitiator complexes.

\section{Effects of complexation on UV-Vis spectra}

The molar extinction coefficient $(\varepsilon)$ of a given photoinitiator describes the portion of incident light of a particular wavelength that is absorbed by the solution. While photoinitiators must have reasonable $\varepsilon$ values at the wavelength of the light source to be effective, very large $\varepsilon$ values are not necessarily indicative of more efficient photoinitiation. ${ }^{24}$ Nevertheless, UV-Vis spectroscopy can be employed to examine the effect of complexation on the energies of the singlet excited states. The UV-Vis spectra of MMMP from 260 - $380 \mathrm{~nm}$, in the presence and absence of $\mathrm{ZnCl}_{2}$ and $\mathrm{AlCl}_{3}$ are illustrated in Fig. 4. Spectra for the visible region are provided in Fig. S2 of the $\mathrm{ESI}$, and show clear absorption tails for both $\mathrm{MMMP} / \mathrm{AlCl}_{3}$ and $\mathrm{MMMP} / \mathrm{ZnCl}_{2}$.

As depicted in Fig. 4, MMMP possesses an intense $\pi \pi^{*}$ transition at around $305 \mathrm{~nm}$, with an $\varepsilon$ value of approximately $1.6 \times 10^{4} \mathrm{~L} \mathrm{~mol}^{-1} \mathrm{~cm}^{-1}$. As illustrated by Fig. 3, $\mathrm{ZnCl}_{2}$ and $\mathrm{AlCl}_{3}$ significantly change the UV spectrum of MMMP; inducing red shifts in its absorbance maximum of 19 and $23 \mathrm{~nm}$, respectively. At $355 \mathrm{~nm}$, the wavelength of a typical PLP experiment, these changes result in an increase in $\varepsilon$ by around an order of magnitude (see Table S1 of ESI).

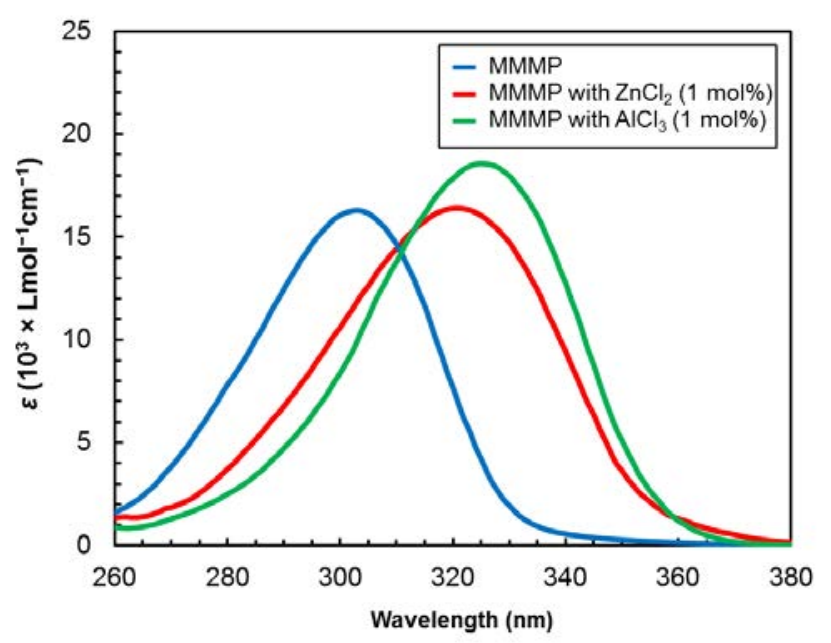

Fig. 4 Molar extinction coefficients $(\varepsilon)$ for MMMP in the EA, EA with added $\mathrm{ZnCl}_{2}$ $\left([\mathrm{ZnCl} 2]_{0} /[\mathrm{EA}]_{0}=1 \%\right)$ and $\mathrm{EA}$ with added $\mathrm{AlCl}_{3}\left([\mathrm{AICl}]_{0} /[\mathrm{EA}]_{0}=1 \%\right)$.

The UV-Vis spectra of DMPA in the presence and absence of $\mathrm{ZnCl}_{2}$ and $\mathrm{AlCl}_{3}$ are presented in Fig. 5. Spectra for the visible region are provided in Fig. S2 of the ESI, and show a clear absorption tail for DMPA/AICl 3 but not DMPA/ZnCl 2 . DMPA has a fairly weak but observable mixed $n \pi^{*}$ transition that occurs at $342 \mathrm{~nm}\left(\varepsilon=2.6 \times 10^{2} \mathrm{~L} \mathrm{~mol}^{-1} \mathrm{~cm}^{-1}\right)$. In addition, an intense 
$\pi \pi^{*}$ transition is observed, with a maximum below $260 \mathrm{~nm}(\varepsilon \sim$ $7 \times 10^{3} \mathrm{~L} \mathrm{~mol}^{-1} \mathrm{~cm}^{-1}$ at $260 \mathrm{~nm}$ ). Complexation of $\mathrm{ZnCl}_{2}$ or $\mathrm{AlCl}_{3}$ dramatically changes the absorbance profile of DMPA; particularly in the $260-320 \mathrm{~nm}$ range. However, addition of $\mathrm{ZnCl}_{2}$ or $\mathrm{AlCl}_{3}$ only slightly affects the $\varepsilon$ value of DMPA at 355 $\mathrm{nm}$ (see Table S1 of ESI).

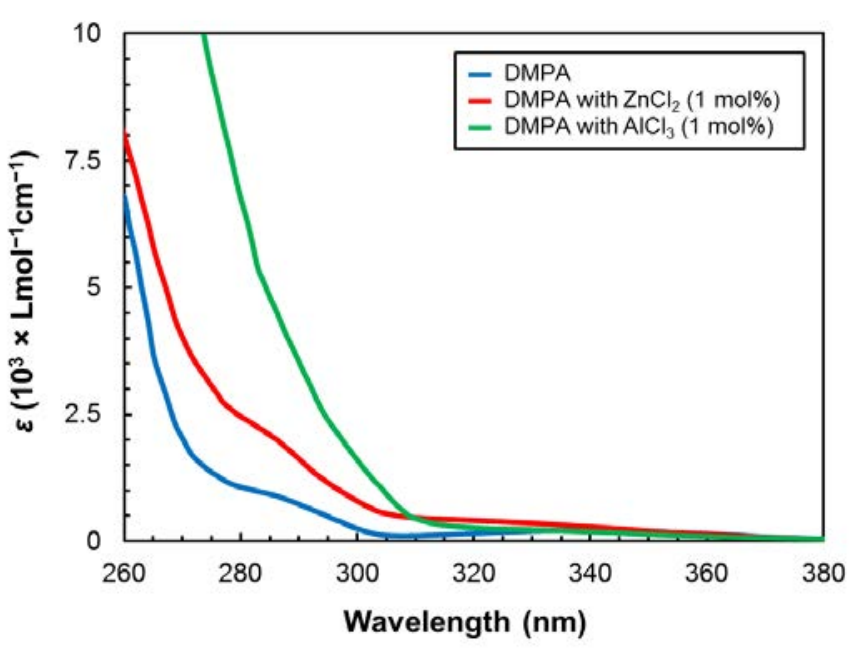

Fig. 5 Molar extinction coefficients $(\varepsilon)$ for DMPA in the EA, EA with added $\mathrm{ZnCl}_{2}$ $\left([\mathrm{ZnCl}]_{0} /[\mathrm{EA}]_{0}=1 \%\right)$ and $\mathrm{EA}$ with added $\mathrm{AlCl}_{3}\left([\mathrm{AICl} 3]_{0} /[\mathrm{EA}]_{0}=1 \%\right)$.

\section{Excited-state energetics and dynamics}

As prototypical radical photoinitiators, acetophenone derivatives have relatively well understood excitation behaviour. In particular, MMMP and DMPA have had their photophysical and photochemical properties characterized in many pioneering studies over the last few decades. ${ }^{55-59}$ The ${ }^{1}\left(n \pi^{*}\right),{ }^{3}\left(\pi \pi^{*}\right)$, and ${ }^{3}\left(n \pi^{*}\right)$ exited states of these species usually intersect in a similar structural region, which leads to short singlet lifetimes, rapid ISCs and minimal fluorescence. ${ }^{60}$ Type I photoinitiators rapidly fragment via $\alpha$-cleavage from their ${ }^{3}\left(n \pi^{*}\right)$ state, while Type II initiators abstract a hydrogen atom from a coinitiating group (usually an alcohol or amine). As the excited states of acetophenone derivatives normally intersect in a similar structural region, time dependent-density functional theory (TD-DFT) calculations were used to investigate the impacts of complexation on photoexcitation behaviour.

The vertical excitations energies to the singlet and triplet states of MMMP as well as the $\left[\mathrm{ZnCl}_{2}(\mathrm{MMMP})\right]$ and $\left[\mathrm{AlCl}_{2}(\mathrm{MMMP})\right]^{+}$complexes, are contrasted in Fig. 6. MMMP is a highly efficient photoinitiator and has relatively straightforward and predictable photoexcitation behaviour (see Fig. 6a). MMMP has a weak $S_{1}$ excited state of $n \pi *$ character that lies below an intense $S_{2} \pi \pi^{*}$ transition. Two essentially degenerate triplet states lie below $S_{1}, T_{1}$ and $T_{2}$, which have $\pi \pi^{*}$ and $n \pi^{*}$ character, respectively. Following excitation to $S_{1}$, a rapid ISC to the triplet manifold would occur, due to the favourable energetic position and matched character of $S_{1}$ and $T_{1}$ (such ${ }^{1}\left(n \pi^{*}\right)$ to ${ }^{3}\left(\pi \pi^{*}\right)$ crossings are allowed by the El-Sayed rules $\left.{ }^{61}\right)$. The near degeneracy of $T_{1}$ and $T_{2}$ would then enable crossing between these states and subsequent $\alpha$-cleavage from the essentially degenerate $n \pi^{*} T_{2}$ state. Normal $a b$ initio calculations were used to estimate the barrier for $\alpha$-cleavage on the triplet surface. a) MMMP

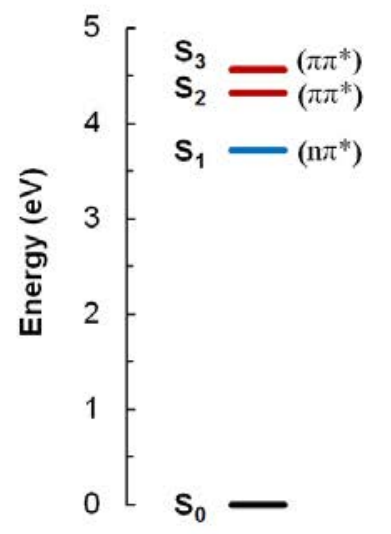

b) $\left[\mathrm{ZnCl}_{2}(\mathrm{MMMP})\right]$

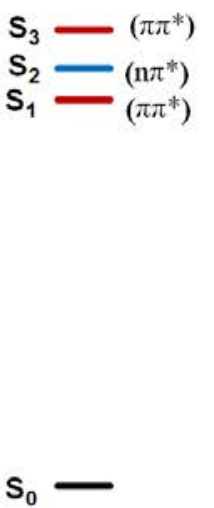

c) $\left[\mathrm{AlCl}_{2}(\mathrm{MMMP})\right]^{+}$

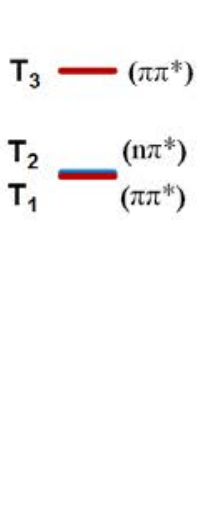

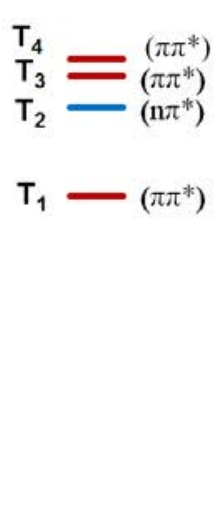

$$
\begin{aligned}
& \mathbf{S}_{3}-\left(\pi \pi^{*}\right) \\
& \mathbf{S}_{2}-\left(\pi \pi^{*}\right) \\
& \mathrm{T}_{4}\left(\mathrm{n} \pi^{*}\right) \\
& \mathrm{S}_{1}-\left(\pi \pi^{*}\right) \\
& \mathbf{T}_{2}-\left(\pi \pi^{*}\right) \\
& \mathrm{T}_{1}-\left(\pi \pi^{*}\right)
\end{aligned}
$$

$\mathrm{S}_{0}-$

Fig. 6 The vertical singlet and triplet excitations states of: a) $\mathrm{MMMP}, \mathrm{b})\left[\mathrm{ZnCl}_{2}(\mathrm{MMMP})\right]$ and c) $\left[\mathrm{AlCl}_{2}\left(\mathrm{MMMP}^{+}\right]^{+}\right.$. The predominant character of each excited state is indicated in parenthesis.

From the optimized $T_{2}$ geometry, $\alpha$-cleavage of MMMP is predicted to be highly kinetically and thermodynamically favourable; proceeding with a small barrier and favourable reaction energy of 20.3 and $-33.4 \mathrm{~kJ} \mathrm{~mol}^{-1}$, respectively (see Fig. S5 of ESI). The calculated excited state and fragmentation behaviour is completely consistent with the short excited singlet and triplet lifetimes of MMMP determined from time resolved laser spectroscopy $\left(\tau_{\mathrm{s} 1}=700 \mathrm{ps}\right.$ and $\tau_{\mathrm{T} 1}=10 \mathrm{~ns}$ in benzene)..$^{57}$

$\mathrm{ZnCl}_{2}$ complexation to MMMP significantly destabilizes the ${ }^{1}\left(n \pi^{*}\right)$ excited state, while concurrently red shifting the ${ }^{1}\left(\pi \pi^{*}\right)$ excitation (see Fig. 6b). While this red shift leads to a significantly higher $\varepsilon$ value at c.a. $355 \mathrm{~nm}$, it is also accompanied by much more complicated photoexcitation behaviour. Aside from the reordering of the $S_{1}$ and $S_{2}$ states, 
the lowest energy ${ }^{3}\left(\pi \pi^{*}\right)$ state $\left(T_{1}\right)$ is almost $1 \mathrm{eV}$ more stable than the ${ }^{3}\left(n \pi^{*}\right)$ state $\left(T_{2}\right)$ (at the $S_{0}$ geometry). Unsurprisingly, an even more dramatic effect is observed following complexation of the more Lewis acidic $\mathrm{AlCl}_{2}{ }^{+}$cation (see Fig. 6c). The effects of $\mathrm{ZnCl}_{2}$ and $\mathrm{AlCl}_{2}{ }^{+}$complexation on the excited states of MMMP can be rationalized by considering their underlying character. As an $n \pi^{*}$ excitation promotes an electron from a localized non-bonding ketone oxygen orbital to a fairly delocalized aromatic $\pi^{*}$ orbital, these excited states would have reduced Lewis basicity at the ketone oxygen atom. Conversely, $\pi \pi^{*}$ type excitations promote an electron from a $\pi$ orbital predominantly associated with the aromatic ring to a reasonably delocalized $\pi^{*}$ orbital that has some ketone oxygen character. Thus, the $\pi \pi^{*}$ type excited states have increased Lewis basicity at the ketone oxygen atom. To illustrate the differences in the basicities of each type of excited state, the electrostatic potential (ESP) surfaces of the $T_{1}\left(\pi \pi^{*}\right)$ and $T_{2}$ $\left(n \pi^{*}\right)$ states of MMMP are provided in Fig. 7. The natural atomic charges (from a Natural Bond Orbital analysis) of the respective ketone and ether oxygen atoms are also indicated.

As shown in Fig. 7 , the ${ }^{3}\left(\pi \pi^{*}\right)$ state of MMMP is significantly more basic on the ketone oxygen atom compared to the ${ }^{3}\left(n \pi^{*}\right)$ state. This difference in basicity explains the stabilizing/ destabilizing effects observed in the excited states of both complexes. Similarly, previous work by Fang and coworkers found that water complexation (H-bonding) to the ketone oxygen atom induces a red shift in the $\pi \pi^{*}$ type excitations of Valerophenone, while concurrently blue shifting the $n \pi *$ excitations. ${ }^{60}$
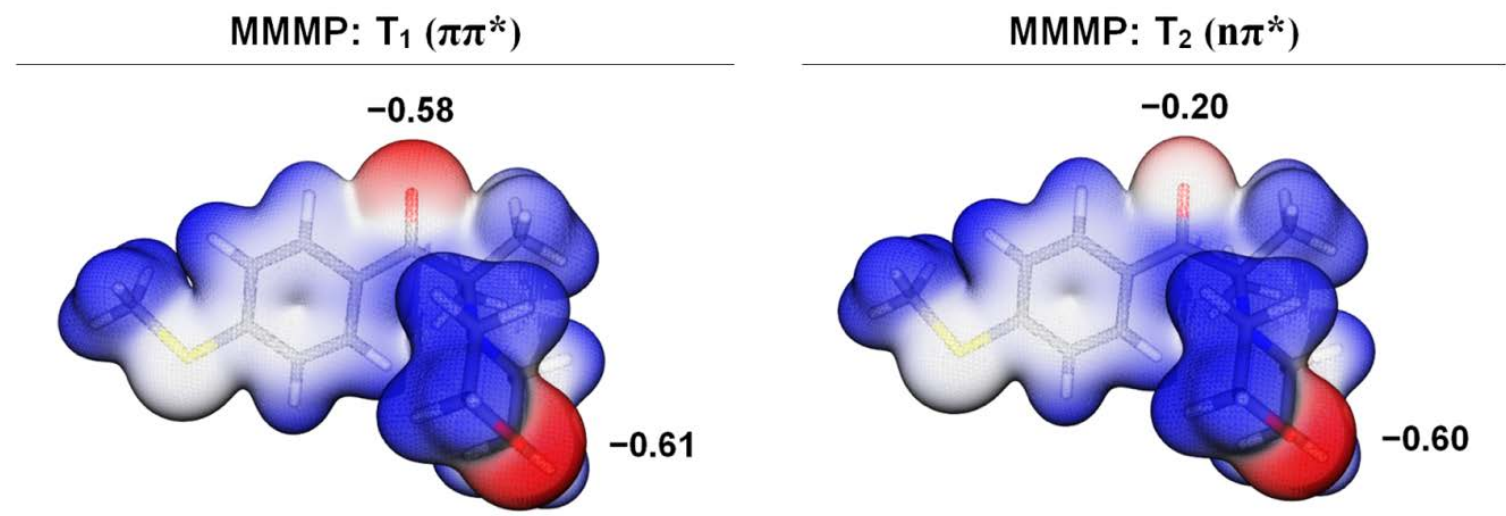

Fig. 7 The contrasting electrostatic potential (ESP) surfaces of MMMP's $\pi \pi^{*}$ and $n \pi^{*}$ triplet excited states. For reference, the natural atomic charges (from a Natural Bond Orbital analysis) of the ketone oxygen atoms are also given.

Analogous excitation profiles of DMPA as well as the $\left[\mathrm{ZnCl}_{2}(\mathrm{DMPA})\right]$ and $\left[\mathrm{AlCl}_{2}(\mathrm{DMPA})\right]^{+}$complexes are illustrated in Fig. 8. TD-DFT calculations indicate that, like MMMP, unbound DMPA has relatively straightforward photoexcitation behaviour (see Fig. 8a). It possesses an $\mathrm{S}_{1}$ state of predominantly $n \pi^{*}$ character, with two triplet states located in the vicinity of $S_{1}$. These $T_{1}$ and $T_{2}$ states have predominantly $n \pi^{*}$ and $\pi \pi^{*}$ character, respectively. The low lying ${ }^{3}\left(\pi \pi^{*}\right)$ state of DMPA likely relays the $S_{1}$ state to $T_{1}$, as the ${ }^{1}\left(n \pi^{*}\right)$ to ${ }^{3}\left(\pi \pi^{*}\right)$ transition is allowed by the El-Sayed rules. Standard $a b$ initio calculations confirm that the $T_{1}$ state of DMPA is of $n \pi^{*}$ character (see ESI Fig. S6) and indicate that $\alpha$-cleavage from this state is highly kinetically and thermodynamically favourable. Indeed, bond scission proceeds with a negligible barrier of $26.3 \mathrm{~kJ} \mathrm{~mol}^{-1}$ and highly favourable reaction energy of $-52.4 \mathrm{~kJ} \mathrm{~mol}^{-1}$ (see ESI Fig. S6). The calculated excited state energies and fragmentation barriers are consistent with the short excited singlet and triplet lifetime of DMPA determined from time resolved laser spectroscopy $\left(\tau_{\mathrm{S} 1}<15 \mathrm{ps}\right.$ and $\tau_{\mathrm{T} 1}=$ $0.25 \mathrm{~ns}$ in benzene)..$^{58}$

Both DMPA complexes have much less predictable excitation behaviour due to analogous destabilization of the $\mathrm{n} \pi^{*}$ states and stabilization of $\pi \pi^{*}$ states (see Fig. $8 \mathrm{~b}$ and $8 \mathrm{c}$ ). While complexation of $\mathrm{ZnCl}_{2}$ does not lead to a reordering of the ${ }^{1}\left(n \pi^{*}\right)$ and ${ }^{1}\left(\pi \pi^{*}\right)$ states, it extensively reorders the corresponding triplet excited states. The lowest energy triplet state $\left(T_{1}\right)$ of $\left[\mathrm{ZnCl}_{2}(\mathrm{DMPA})\right]$, which has predominantly $\pi \pi^{*}$ character, is ca. $0.3 \mathrm{eV}$ more stable than the nearest $n \pi^{*}$ type state $\left(T_{2}\right)$. Unsurprisingly, $\mathrm{AlCl}_{2}{ }^{+}$coordination has an even larger effect. The $S_{1}, S_{2}$ and $S_{3}$ excited states of the $\left[\mathrm{AlCl}_{2}(\mathrm{DMPA})\right]^{+}$all possess predominantly $\pi \pi^{*}$ character, while the intense $\mathrm{S}_{4}$ state was found to have mixed character. On the triplet surface, $T_{1}$ was found to be ca. $0.7 \mathrm{eV}$ more stable than the nearest state $T_{2}$ (which has mixed character). Two other triplet states, $T_{3}$ and $T_{4}$, of $\pi \pi^{*}$ character are located in the vicinity of $T_{2}$. Clearly both complexes have much more complicated photoexcitation behaviour than unbound DMPA.

\section{Effects of complexation on photoinitiator photolysis}

Complexation of Lewis acids to the ketone moiety of MMMP and DMPA clearly affects the energetics of the excited states. However, as noted in the introduction, quantum initiation yield depends on the rates of various competing photophysical and -chemical processes. This makes it difficult to quantitatively determine initiator efficiency using theoretical techniques alone. Nonetheless, we can draw some more qualitative conclusions by considering some of the effects of complexation, drawing from previous literature where relevant.

For efficient photoinitiation, the ISC must outcompete both fluorescence and internal conversion. The $\left[\mathrm{ZnCl}_{2}\right.$ (DMPA)] complex retains a ${ }^{1}\left(n \pi^{*}\right)$ state as the lowest energy singlet 
excited state. It is probable that ISCs in these complexes would proceed to the nearest ${ }^{3}\left(\pi \pi^{*}\right)$ state $\left(T_{3}\right)$. The $\left[\mathrm{ZnCl}_{2}(\mathrm{MMMP})\right]$, $\left[\mathrm{AlCl}_{2}(\mathrm{MMMP})\right]^{+}$and the $\left[\mathrm{AlCl}_{2}(\mathrm{DMPA})\right]^{+}$complexes have their ${ }^{1}\left(n \pi^{*}\right)$ and ${ }^{1}\left(\pi \pi^{*}\right)$ inverted. Although it is not clear what effect this inversion may have on the rate of ISC, we note that ${ }^{1}\left(\pi \pi^{*}\right)$ to ${ }^{3}\left(n \pi^{*}\right)$ crossings are also El-Sayed allowed. ${ }^{61}$ Moreover, as Marian noted in an excellent review, ${ }^{62}$ vibronic interactions can also significantly increase the rates of El-Sayed-forbidden inter-system crossings. ${ }^{63-66}$ Additionally, $\mathrm{Al}, \mathrm{Cl}$ and $\mathrm{Zn}$ would be expected to exert a modest heavy atom effect, ${ }^{61}$ which may also increase the rate of ISCs.

The differences in the triplet surfaces of the complexes compared with their parent photoinitiators is striking. The lowest energy triplet state of these complexes have $\pi \pi^{*}$ character and the nearest $n \pi^{*}$ states lie significantly above $T_{1}$ (c.a. $0.3-2.0 \mathrm{eV}$ ). This reordering could potentially lead to much slower rates of photolysis and longer triplet lifetimes, as ${ }^{3}\left(\pi \pi^{*}\right)$ states do not readily undergo fragmentation. ${ }^{60}$ Recent work has demonstrated that various amine-substituted benzoin derivatives, which also possess a multitude of low lying $\left(\pi \pi^{*}\right)$ type triplet states, have very long triplet lifetimes and are uncharacteristically poor photoinitiators. ${ }^{24}$ Moreover, as Fang and co-workers outlined, analogous reordering of ${ }^{3}\left(\pi \pi^{*}\right)$ and ${ }^{3}\left(n \pi^{*}\right)$ states in valerophenone significantly lengthens triplet lifetimes in aqueous solution. ${ }^{60}$ In this regard, a) DMPA

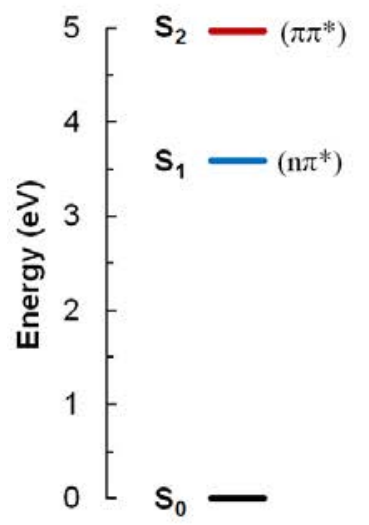

b) $\left[\mathrm{ZnCl}_{2}\right.$ (DMPA)]

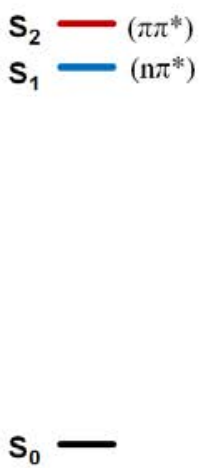

c) $\left[\mathrm{AlCl}_{2}(\mathrm{DMPA})\right]^{+}$

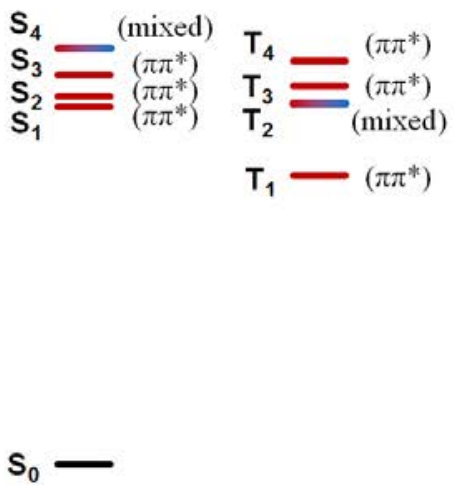

Fig. 8 The vertical singlet and triplet excitations of: a) DMPA, b) $\left[\mathrm{ZnCl}_{2}(\mathrm{DMPA})\right]$ and c) $\left[\mathrm{AlCl}_{2}(\mathrm{DMPA})\right]^{+}$. The predominant character of each excited state is indicated in parenthesis.

our TD-DFT calculations predict that Lewis acids exert much more significant energetic effects on the triplet $n \pi^{*}$ and $\pi \pi^{*}$ states.

It is perhaps tempting to conclude, unequivocally, that Lewis acid complexation would lead to longer triplet lifetimes and poorer photoinitiation behaviour. However, Fang and coworkers also noted that the barriers for both 1,5- $\mathrm{H}$ atom transfer and $\alpha$-cleavage in valerophenone were significantly lowered by $\mathrm{H}$-bonding in aqueous solvation. ${ }^{60}$ Moreover, an elegant study by Fouassier and co-workers found that the triplet lifetime of MMMP decreases significantly with increasing solvent polarity and is notably shorter in protic solvents, such as ethanol and isopropanol. ${ }^{57}$

While it is not possible here to determine the barrier to $\alpha$ cleavage of the DMPA or MMMP complexes quantitatively, we note that fragmentation increases the ketone oxygen basicity of unbound MMMP and DMPA. According to natural atomic charges, the transition state for $\alpha$-cleavage and the product acyl radicals are both significantly more Lewis basic than the respective ${ }^{3}\left(n \pi^{*}\right)$ state (see Fig. S5 and S6 of ESI). Hence, Lewis acid complexation at the ketone moiety would stabilize the $\alpha$ cleavage transition states and product acyl radicals more significantly than the reactant ${ }^{3}\left(n \pi^{*}\right)$ states. Depending on the extent of this stabilization, the ${ }^{3}\left(n \pi^{*}\right)$ states of these complexes may even become dissociative and could potentially intersect the $\mathrm{T}_{1}{ }^{3}\left(\pi \pi^{*}\right)$ state as the $\mathrm{C}-\mathrm{C}$ bond undergoes normal vibrational stretching.

In summary, while Lewis acid complexation can red-shift the intense $\pi \pi^{*}$ absorption of acetophenone photoinitiators and dramatically increase their UV-absorbance at particular wavelengths, these changes are not necessarily reflective of more effective homolysis. Our calculations demonstrate that these changes are accompanied by significant destabilization of the crucially important $n \pi^{*}$ excited states. While photolysis is still expected, and could potentially even occur into the visible region, it is accompanied by more complex photodynamics and possibly longer triplet lifetimes. These effects could help to explain our observed loss of PLP characteristics (particularly at high pulse rates), under conditions that are effective in the absence of Lewis acid.

\section{Effect of Lewis acids on fragment stability and reactivity}

For a photoinitiator to be effective, at least one of the fragments generated from homolysis must rapidly react with monomer to initiate polymer chain growth. Indeed, a fundamental assumption of PLP kinetic experiments is that the rate coefficient for the addition of photoinitiator fragments to monomer $\left(k_{\text {add }}\right)$ is significantly faster than propagation $\left(k_{\mathrm{p}}\right)$ and so initiation is not rate limiting. Photolysis of MMMP forms two highly reactive radical fragments; a thio-substituted benzoyl acyl radical ( $T$ rad) and a morpholine-substituted 
isopropyl radical ( $\mathrm{M}$ rad) (see Fig. 2). In contrast, photolysis of DMPA results in fragments that are more differentiated in reactivity; a highly reactive benzoyl acyl radical ( $\mathrm{rad}$ ) and a relatively unreactive dimethoxy substituted benzyl type radical (D rad) (see Fig. 2). ${ }^{59}$ Experimental estimates of $k_{\text {add }}$ for the B rad reacting with MMA are of the order of $10^{5} \mathrm{~L} \mathrm{~mol}^{-1} \mathrm{~s}^{-1} .67$

As the reactivity of the radical fragments towards monomer underpins the success or failure of photoinitiation, we sought to quantify and rationalize the effect of Lewis acid coordination on fragment reactivity. As such, we used highlevel ab initio quantum chemistry to calculate rate coefficients for addition of these fragment radicals to MMA monomer $\left(k_{\text {add }}\right)$. Prior to performing these calculations, we verified that our methodology could accurately predict experimentally determined rate coefficients for similar addition reactions (see Table S3 and Fig. S3 in ESI). We noted excellent agreement (to within a factor of 3 ) between theoretically predicted and experimentally determined rate coefficients for these benchmarking reactions. We should also emphasize that very similar methodology has been extensively benchmarked in numerous studies over the last decade and its accuracy is well established. ${ }^{46-48}$

The $k_{\text {add }}$ values for various addition reactions were calculated from first principles to explore the effects of Lewis acid complexation on radical fragment reactivity. For these calculations we used $\mathrm{AlCl}_{3}$ as a model Lewis acid and rigorously examined coordination to the radical fragment (in all positions where Lewis acid coordination was observed in Fig. 2) and also to ester group of adding MMA monomer. Table 2 details the reaction energetics for the addition of these various initiator fragments under these different binding scenarios. To assist efforts to rationalize these $k_{\text {add }}$ values, gas-phase reaction enthalpies $\left(\Delta \mathrm{H}_{\text {gas }}\right)$ and the sum of the radical fragment ionization energy and electron affinity of $M M A\left(I_{R}+E A_{M}\right)$ were also calculated. The effect of $\mathrm{AlCl}_{3}$ complexation on the radical stabilization energies (RSEs) of the fragment radicals was also examined. The sum of the radical ionization energy and monomer electron affinity $\left(\mathrm{IE}_{R}+E \mathrm{~A}_{M}\right)$ is frequently used to assess the importance of polar-effects in radical addition reactions; non-negligible charge transfer is indicated by an $I E_{R}$ $+E A_{M}$ value of $<7-8 \mathrm{eV}$, with lower values signifying greater polar stabilization of the transition state. ${ }^{68}$ Many radical-based transfer, addition and fragmentation reactions obey the BellEvans-Polanyi principle. ${ }^{69,} 70$ Thus, RSE and $\Delta H_{\text {gas }}$ values can be used to infer changes in reactivity caused by general enthalpic effects.

As outlined in Table 1, the following order of reactivity with MMA is obtained for the unmediated addition reactions: $M$ rad $>\mathrm{T}$ rad $\sim \mathrm{B}$ rad $>\mathrm{D}$ rad. This ordering can be rationalized by considering the enthalpic and polar characteristics of these reactions. As would be anticipated from their RSEs, addition of the $B$ rad and $T$ rad fragments is enthalpically highly favourable but relatively minor amounts of polar stabilization are observed. In contrast, the D rad fragment has more nucleophilic character but the corresponding addition reaction is less enthalpically favourable because this radical is both fairly hindered and extensively delocalized. The tertiary $M$ rad has the least favourable reaction enthalpy (because of high steric hindrance) but it is also highly nucleophilic and so the corresponding addition reaction is strongly favoured by polar effects.

As Table 1 illustrates, $\mathrm{AlCl}_{3}$ coordination to the radical fragment has a highly variable effect on reactivity. The following order of reactivity was obtained for the $\mathrm{AlCl}_{3}$ complexed radical fragments: $\mathrm{M}$ rad ( $\mathrm{O}$ bound) $>\mathrm{T}$ rad $\sim \mathrm{B}$ rad $>\mathrm{M}$ rad ( $\mathrm{N}$ bound) $>\mathrm{D}$ rad. The predicted $k_{\text {add }}$ values for the addition of the $\mathrm{AlCl}_{3}$ complexed $\mathrm{B}$ rad and $\mathrm{T}$ rad fragments to MMA are $1.15 \times 10^{6}$ and $1.18 \times 10^{6} \mathrm{~L} \mathrm{~mol}^{-1} \mathrm{~s}^{-1}$, respectively; approximately an order of magnitude faster than the corresponding unmediated reactions. In contrast, complexation of $\mathrm{AlCl}_{3}$ to the $\mathrm{M}$ rad (at the amine $\mathrm{N}$ ) and to the $D$ rad significantly reduces the reactivity of these radicals, with $k_{\text {add }}$ values of only 6.54 and $3.29 \mathrm{~L} \mathrm{~mol}^{-1} \mathrm{~s}^{-1}$, respectively. Unsurprisingly, complexation of $\mathrm{AlC}_{3}$ at the remote ether moiety of the $\mathrm{M}$ rad had essentially no effect on its reactivity.

Pleasingly, this quite divergent reactivity behaviour can be rationalized by considering the differing importance of enthalpic and polar effects in the respective systems. The conjugate $n$-donor groups of the $M$ rad and $D$ rad do not delocalize their respective radicals as effectively as the equivalent acyl oxygen atoms of the $\mathrm{B}$ rad and $\mathrm{T}$ rad. Consequently, complexation of $\mathrm{AlCl}_{3}$ to the $\mathrm{D}$ rad and $\mathrm{M}$ rad only modestly destabilizes the respective radicals and actually decreases the favourability of $\Delta \mathrm{H}_{\text {gas. }}$ Moreover, $\mathrm{AlCl}_{3}$ complexation significantly reduces the inherent nucleophilic character of these radicals, which results in significantly less charge-transfer stabilization of the respective transition states. In other words, for the $\mathrm{M}$ rad and $\mathrm{D}$ rad, $\mathrm{AlCl}_{3}$ complexation has a very detrimental effect on charge-transfer stabilization, which is not countered by increased enthalpic favourability.

In contrast, $\mathrm{AlCl}_{3}$ complexation greatly destabilizes both acyl radicals (i.e., $B$ rad and $\mathrm{T}$ rad) and consequently the $\Delta \mathrm{H}_{\text {gas }}$ for the respective addition reactions is around $70 \mathrm{~kJ} \mathrm{~mol}^{-1}$ more favourable in the presence of Lewis acid. Thus, the enhanced reactivity of the $B$ rad and $T$ rad following complexation to the adjacent $\mathrm{n}$ donor (acyl $\mathrm{O}$ atom) can be assigned to significant localization of the respective radicals. These acyl radicals are inherently less nucleophilic and so the reduction in charge-transfer stabilization following $\mathrm{AlCl}_{3}$ complexation is more than compensated by the increased enthalpic favourability of MMA addition.

Interestingly, significant radical destabilization is observed following $\mathrm{AlCl}_{3}$ complexation to all photoinitiator fragment radicals (see the RSE values in Table 1 ). As a result of this destabilization, these photoinitiator fragment radicals are significantly weaker Lewis bases than their ground-state parent photoinitiators and, more significantly, MMA monomer. Consequently, thermodynamic speciation of the $\mathrm{ZnCl}_{2}$ and $\mathrm{AlCl}_{3}$ would result in Lewis acid coordination at the ester side-chain of MMA monomer, rather than to these fragment radicals. However, as it is unclear if ligand exchange kinetics would be sufficiently rapid to allow Lewis acid repositioning following photolysis, addition of uncomplexed 
photoinitiator fragment radicals to $\left[\mathrm{AlCl}_{3}(\mathrm{MMA})\right]$ was also investigated.

As indicated in Table 1, coordination of $\mathrm{AlCl}_{3}$ at the conjugate ester side-chain of MMA also has a significant effect on $k_{\text {add }}$. For $\left[\mathrm{AlCl}_{3}(\mathrm{MMA})\right]$, the following order of radical reactivity is obtained: $M$ rad $>D$ rad $>T$ rad $>B$ rad. The predicted $k_{\text {add }}$ values for the addition of the $\mathrm{B}$ rad and $\mathrm{T}$ rad fragments to complexed MMA are over two orders of magnitude faster than the corresponding unmediated reactions. More remarkably, the rate of addition of the $D$ rad to complex MMA exceeds the diffusion limit $10^{8} \mathrm{~L} \mathrm{~mol}^{-1} \mathrm{~s}^{-1}$, and is more than 4 orders of magnitude faster than the unmediated reaction. While no formal transition state for the addition of the $\mathrm{M}$ rad to $\mathrm{AlCl}_{3}$-complexed MMA could be identified, we believe this reaction proceeds via outer-sphere electron transfer (OSET) with a subsequent recombination of the formed cation and radical anion. For the purposes of the present work, we have assumed that this reaction is also diffusion limited.

The remarkable catalysis observed with $\mathrm{AlCl}_{3}$ complexation to the methyl ester of MMA can be largely attributed to polar effects, although minor enthalpic increases are also observed. Complexation of $\mathrm{AlCl}_{3}$ to MMA lowers its electron affinity by more than $2 \mathrm{eV}$, strongly enhancing the monomer's inherent electrophilic character. Consequently, charge transfer effects dominate these reactions, with the $k_{\text {add }}$ values directly

Table 1 The effect of $\mathrm{AlCl}_{3}$-complexation on the calculateda rate coefficient for initiator fragment addition to MMA ( $\left.k_{\text {add }}\right)$. To assist the rationalization, radical stabilization energies (RSEs), gas-phase reaction enthalpies $\left(\Delta \mathrm{H}_{\mathrm{gas}}\right)$ and sum of the radical ionization energy and monomer electron affinity $\left(\mathrm{IE}_{\mathrm{R}}+\mathrm{EA}_{\mathrm{M}}\right)$ were also calculated. ${ }^{\mathrm{a}}$

\begin{tabular}{|c|c|c|c|c|c|c|}
\hline $\begin{array}{l}\text { Initiator Fragment/ } \\
\text { Lewis acid }\end{array}$ & $\begin{array}{l}\text { Monomer/ } \\
\text { Lewis acid }\end{array}$ & $\begin{array}{c}\text { RSE } \\
\left(\mathrm{kJ} \mathrm{mol}^{-1}\right)\end{array}$ & $\begin{array}{c}\Delta \mathrm{H}_{\text {gas }} \\
\left(\mathrm{kJ} \mathrm{mol}^{-1}\right)\end{array}$ & $\begin{array}{c}\mathrm{IE}_{\mathrm{R}}+\mathrm{EA} \mathrm{A}_{\mathrm{M}} \\
(\mathrm{eV})\end{array}$ & $\begin{array}{c}\Delta \mathrm{G}^{ \pm}{ }_{\text {sol }} \\
\left(\mathrm{kJ} \mathrm{mol}^{-1}\right)\end{array}$ & $\begin{array}{c}k_{\text {add }} \\
\left(\mathrm{L} \mathrm{mol}^{-1} \mathrm{~s}^{-1}\right)\end{array}$ \\
\hline B rad & MMA & 53.3 & -109.7 & 6.65 & 45.6 & $1.26 \times 10^{5}$ \\
\hline $\mathrm{B} \mathrm{rad} / \mathrm{AlCl}_{3}$ & MMA & 3.9 & -179.9 & 7.25 & 39.4 & $1.55 \times 10^{6}$ \\
\hline B rad & $\mathrm{MMA} / \mathrm{AlCl}_{3}$ & 53.3 & -125.5 & 4.51 & 34.1 & $1.29 \times 10^{7}$ \\
\hline T rad & MMA & 53.4 & -110.7 & 6.30 & 44.3 & $2.14 \times 10^{5}$ \\
\hline $\mathrm{T} \mathrm{rad} / \mathrm{AlCl}_{3}$ & MMA & 3.8 & -178.7 & 7.01 & 40.1 & $1.18 \times 10^{6}$ \\
\hline T rad & $\mathrm{MMA} / \mathrm{AlCl}_{3}$ & 53.4 & -127.6 & 4.17 & 30.5 & $5.64 \times 10^{7}$ \\
\hline D rad & MMA & 65.9 & -99.9 & 5.88 & 52.1 & $9.14 \times 10^{3}$ \\
\hline $\mathrm{D} \mathrm{rad} / \mathrm{AlCl}_{3}$ & MMA & 46.9 & -91.8 & 6.80 & 71.8 & 3.29 \\
\hline D rad & $\mathrm{MMA} / \mathrm{AlCl}_{3}$ & 65.9 & -130.8 & 3.75 & 24.4 & $6.74 \times 10^{8}$ \\
\hline M rad & MMA & 48.3 & -95.1 & 5.15 & 37.2 & $3.85 \times 10^{6}$ \\
\hline $\mathrm{M} \mathrm{rad} / \mathrm{AlCl}_{3}$ (O bound) & MMA & 43.3 & -103.3 & 5.68 & 37.5 & $3.33 \times 10^{6}$ \\
\hline $\mathrm{M} \mathrm{rad} / \mathrm{AlCl}_{3}$ ( $\mathrm{N}$ bound) & MMA & 39.0 & -82.2 & 6.45 & 70.0 & 6.54 \\
\hline M rad & $\mathrm{MMA} / \mathrm{AlCl}_{3}$ & 48.3 & -121.3 & 3.02 & $<20$ & $>10^{9}$ \\
\hline
\end{tabular}

aAll values were calculated at $25^{\circ} \mathrm{C}$. The $\mathrm{T}$ and $\mathrm{M}$ radicals result from photodissociation of MMMP; the B and D radicals are from DMPA (see Fig. 2 ). All $k_{\text {add }}$ values were corrected (by a factor of 2 ) for reaction path degeneracy.

correlated with radical nucleophilicity (as measured by their ionization energies). In summary, complexation of the $\mathrm{AlCl}_{3}$ to acyl initiator fragments greatly increases their reactivity toward monomer through radical destabilization effects. For the $M$ rad and $D$ rad complexes, this destabilization is more modest, and less favourable charge-transfer actually slows addition to MMA. If ligand exchange were to occur, complexation of $\mathrm{AlCl}_{3}$ to MMA monomer would then significantly increase the reactivity of all initiator fragments via polar effects. As a weaker Lewis acid than $\mathrm{AlCl}_{3}, \mathrm{ZnCl}_{2}$ would have less dramatic effects on fragment radical stability and the electrophilicity of MMA. Nonetheless, analogous (though more modest) changes to $k_{\text {add }}$ would also be expected in the corresponding $\mathrm{ZnCl}_{2}$ systems. Conversely, as a stronger Lewis acid than $\mathrm{AlCl}_{3}, \mathrm{AlCl}_{2}{ }^{+}$would likely exert an even larger kinetic effect. Unfortunately, high-level reactivity calculations using realistically solvated $\mathrm{ZnCl}_{2}$ or $\mathrm{AlCl}_{2}{ }^{+}$species are intractable.

\section{Conclusions and Implications}

Several important conclusions regarding the effect of Lewis acid complexation on acetophenone photoinitiators can be made. Where reasonable, these conclusions have been generalized so as to be more broadly applicable to other photoinitiator/ Lewis acid combinations.

Lewis acid complexation at the ketone moiety induces significant changes in the UV-Vis spectra of acetophenone derivatives. These changes will have a variable effect on absorbance, depending on the combination of photoinitiator and Lewis acid, and the wavelength of the incident light source. Lewis acids that possess multiple free coordination sites, or readily displaceable anionic ligands (particularly -OTf or $-\mathrm{NTf}_{2}$ ), are likely to form 5-membered chelates with any acetophenone derivatives that have either nitrogen or oxygen based functionality in the $\gamma$ position. Such chelate complexes will probably be more stable than monomer solvated Lewis acid complexes and will have lower initiation efficiencies because of stronger solvent cage effects. Bulkier Lewis acids, such as trivalent halides, are less likely to form chelate complexes without displacement of anionic ligands and thus may interact less selectively with the photoinitiator at low Lewis acid concentrations. The use of bulkier photoinitiators, such as adamantane and norbornane substituted acetophenones, ${ }^{71}$ may aid future PLP experiments with strong Lewis acids.

While it is a bulky Lewis acid, the behaviour of $\mathrm{AlCl}_{3}$ requires special comment. Theoretical calculations indicate 
that in its neutral form, $\mathrm{AlCl}_{3}$ would not interact significantly with MMMP under competing solvation by MMA. Moreover, the predominant ether-bound $\left[\mathrm{AlCl}_{3}(\mathrm{MMMP})\right]$ complex would have similar photoexcitation behaviour to that of uncomplexed MMMP. However, MMMP could readily displace monomer from $\left[\mathrm{AlCl}_{2}(\mathrm{MMA})_{3}\right]^{+}$cation, which forms from the self-ionization of $\left[\mathrm{AlCl}_{3}(\mathrm{MMA})\right]$. As this self-ionization process is itself concentration dependent, the effects of Lewis acids on initiation may vary depending on the reaction conditions.

In the present work, Lewis acid complexation to acetophenone derivatives was found to significantly red-shift their UV-Vis spectra, raising hope that these types of systems may be used in the visible region. Indeed, studies in this direction are now underway. However, the observed spectral changes result from significant stabilization and destabilization of underlying $\pi \pi^{*}$ and $n \pi^{*}$ excited states, resulting in more complicated excitation dynamics. Indeed, longer triplet lifetimes, slower photolysis and lower radical concentrations may be observed. As Lewis acids may adversely affect the triplet life-times of photoinitiators, high-flashing rate PLP experiments should be attempted with some caution.

In addition, Lewis acid complexation has a significant effect on the stability and reactivity of photoinitiator radicals. Coordination of Lewis acids to acyl fragments localizes and considerably destabilizes these radicals, significantly increasing reactivity towards monomer. Lewis acid coordination also localizes and destabilizes dimethoxy phenyl and morpholine substituted isopropyl radicals, although to a smaller extent, while making these radicals less reactive towards MMA. For all of the photoinitiator fragments examined, $\left[\mathrm{AlCl}_{3}(\mathrm{MMA})\right]$ was found to be considerably more reactive than uncomplexed monomer; with $k_{\text {add }}$ increasing by $2-4$ orders of magnitude, depending on the identity of the adding fragment radical.

Remarkably, Lewis acids have the potential to significantly affect all aspects of photoinitiation. Understanding these effects will greatly aid in the selection of appropriate photoinitiators for PLP kinetic studies of Lewis acid-mediated radical polymerization, and more generally with the design of novel visible light photoinitiating systems.

\section{Acknowledgements}

MLC gratefully acknowledges support from the Australian Research Council under its Discovery Projects program (DP150104454) and generous allocations of supercomputing time on the National Facility of the Australian National Computational Infrastructure.

\section{Notes and references}

1. O. F. Olaj, I. Bitai and F. Hinkelmann, Die Makromolekulare Chemie, 1987, 188, 1689-1702.

2. M. L. Coote, M. D. Zammit and T. P. Davis, Trends Polym. Sci., 1996, 4, 189-196.

3. S. Beuermann and M. Buback, Prog Polym Sci, 2002, 27, 191254.
4. M. Buback, M. Busch and R. A. Lämmel, Macromolecular Theory and Simulations, 1996, 5, 845-861.

5. S. Beuermann, Macromolecules, 2002, 35, 9300-9305.

6. P. Castignolles, A. N. Nikitin, L. Couvreur, G. Mouraret, B. Charleux and J.-P. Vairon, Macromol Chem Physic, 2006, 207, 81-89.

7. J. M. Asua, S. Beuermann, M. Buback, P. Castignolles, B. Charleux, R. G. Gilbert, R. A. Hutchinson, J. R. Leiza, A. N. Nikitin, J.-P. Vairon and A. M. van Herk, Macromol Chem Physic, 2004, 205, 2151-2160.

8. C. Barner-Kowollik, S. Beuermann, M. Buback, P. Castignolles, B. Charleux, M. L. Coote, R. A. Hutchinson, T. Junkers, I. Lacik, G. T. Russell, M. Stach and A. M. van Herk, Polym Chem-Uk, 2014, 5, 204-212.

9. S. Beuermann, M. Buback, T. P. Davis, R. G. Gilbert, R. A. Hutchinson, O. F. Olaj, G. T. Russell, J. Schweer and A. M. van Herk, Macromol Chem Physic, 1997, 198, 1545-1560.

10. S. Beuermann, M. Buback, T. P. Davis, R. G. Gilbert, R. A. Hutchinson, A. Kajiwara, B. Klumperman and G. T. Russell, Macromol Chem Physic, 2000, 201, 1355-1364.

11. S. Beuermann, M. Buback, T. P. Davis, N. García, R. G. Gilbert, R. A. Hutchinson, A. Kajiwara, M. Kamachi, I. Lacík and G. T. Russell, Macromol Chem Physic, 2003, 204, 1338-1350.

12. M. Buback, R. G. Gilbert, R. A. Hutchinson, B. Klumperman, F.-D. Kuchta, B. G. Manders, K. F. O'Driscoll, G. T. Russell and J. Schweer, Macromol Chem Physic, 1995, 196, 3267-3280.

13. I. Lacík, A. Chovancová, L. Uhelská, C. Preusser, R. A. Hutchinson and M. Buback, Macromolecules, 2016, 49, 32443253.

14. J. P. Fouassier and J. Lalevee, Photoinitiators for Polymer Synthesis: Scope, Reactivity and Efficiency, Wiley-VCH, Weinheim, 2012.

15. B. B. Noble, L. M. Smith and M. L. Coote, Polym Chem-Uk, 2014, 5, 4974-4983.

16. S. Pedrón, J. Guzmán and N. García, Macromol Chem Physic, 2011, 212, 860-869.

17. S. Harrisson, S. R. Mackenzie and D. M. Haddleton, Chem Commun, 2002, 2850-2851.

18. S. Harrisson, S. R. Mackenzie and D. M. Haddleton, Macromolecules, 2003, 36, 5072-5075.

19. I. Woecht, G. Schmidt-Naake, S. Beuermann, M. Buback and N. García, J. Polym. Sci. A Polym. Chem., 2008, 46, 14601469.

20. G. Schmidt-Naake, I. Woecht and A. Schmalfuß, Macromol Symp, 2007, 259, 226-235.

21. G. Schmidt-Naake, I. Woecht, A. Schmalfuß and T. Glück, Macromol Symp, 2009, 275-276, 204-218.

22. A. Jeličić, S. Beuermann and N. García, Macromolecules, 2009, 42, 5062-5072.

23. A. Jeličić, F. Köhler, A. Winter and S. Beuermann, J. Polym. Sci. A Polym. Chem., 2010, 48, 3188-3199.

24. E. Frick, C. Schweigert, B. B. Noble, H. A. Ernst, A. Lauer, Y. Liang, D. Voll, M. L. Coote, A.-N. Unterreiner and C. BarnerKowollik, Macromolecules, 2016, 49, 80-89.

25. S. Hu, R. Popielarz and D. C. Neckers, Macromolecules, 1998, 31, 4107-4113. 
26. P. Xiao, W. Hong, Y. Li, F. Dumur, B. Graff, J. P. Fouassier, D. Gigmes and J. Lalevée, Polymer, 2014, 55, 746-751.

27. J. Zhang, M. Frigoli, F. Dumur, P. Xiao, L. Ronchi, B. Graff, F. Morlet-Savary, J. P. Fouassier, D. Gigmes and J. Lalevée, Macromolecules, 2014, 47, 2811-2819.

28. R. Liska and D. Herzog, J. Polym. Sci. A Polym. Chem., 2004, 42, 752-764.

29. M.-A. Tehfe, F. Dumur, B. Graff, J.-L. Clément, D. Gigmes, F. Morlet-Savary, J.-P. Fouassier and J. Lalevée, Macromolecules, 2013, 46, 736-746.

30. S. Jockusch, M. S. Landis, B. Freiermuth and N. J. Turro, Macromolecules, 2001, 34, 1619-1626.

31. D. S. Esen, N. Arsu, J. P. Da Silva, S. Jockusch and N. J. Turro, J. Polym. Sci. A Polym. Chem., 2013, 51, 1865-1871.

32. T. J. A. Wolf, D. Voll, C. Barner-Kowollik and A.-N. Unterreiner, Macromolecules, 2012, 45, 2257-2266.

33. E. Frick, H. A. Ernst, D. Voll, T. J. A. Wolf, A.-N. Unterreiner and C. Barner-Kowollik, Polym Chem-Uk, 2014, 5, 5053-5068.

34. Y. Zhao and D. G. Truhlar, Theoretical Chemistry Accounts, 2007, 120, 215-241.

35. W. J. Hehre, R. Ditchfield and J. A. Pople, The Journal of Chemical Physics, 1972, 56, 2257-2261.

36. J. D. Dill and J. A. Pople, The Journal of Chemical Physics, 1975, 62, 2921-2923.

37. T. Clark, J. Chandrasekhar, G. W. Spitznagel and P. V. R. Schleyer, Journal of Computational Chemistry, 1983, 4, 294-301.

38. M. M. Francl, W. J. Pietro, W. J. Hehre, J. S. Binkley, M. S. Gordon, D. J. DeFrees and J. A. Pople, The Journal of Chemical Physics, 1982, 77, 3654-3665.

39. M. J. Frisch, J. A. Pople and J. S. Binkley, The Journal of Chemical Physics, 1984, 80, 3265-3269.

40. V. A. Rassolov, J. A. Pople, M. A. Ratner and T. L. Windus, The Journal of Chemical Physics, 1998, 109, 1223-1229.

41. I. M. Alecu, J. Zheng, Y. Zhao and D. G. Truhlar, Journal of Chemical Theory and Computation, 2010, 6, 2872-2887.

42. D. J. Henry, M. B. Sullivan and L. Radom, J. Chem. Phys., 2003, 118, 4849-4860.

43. M. L. Coote, E. H. Krenske and E. I. Izgorodina, Macromol Rapid Comm, 2006, 27, 473-497.

44. E. I. Izgorodina, D. R. B. Brittain, J. L. Hodgson, E. H. Krenske, C. Y. Lin, M. Namazian and M. L. Coote, The Journal of Physical Chemistry A, 2007, 111, 10754-10768.

45. A. V. Marenich, C. J. Cramer and D. G. Truhlar, The Journal of Physical Chemistry B, 2009, 113, 6378-6396.

46. C. Y. Lin, E. I. Izgorodina and M. L. Coote, Macromolecules, 2010, 43, 553-560.

47. E. I. Izgorodina and M. L. Coote, Chem. Phys., 2006, 324, 96110.

48. B. B. Noble and M. L. Coote, International Reviews in Physical Chemistry, 2013, 32, 467-513.

49. R. D. Gaussian 09 and G. W. T. M. J. Frisch, H. B. Schlegel, G. E. Scuseria, M. A. Robb, J. R. Cheeseman, G. Scalmani, V. Barone, B. Mennucci, G. A. Petersson, H. Nakatsuji, M. Caricato, X. Li, H. P. Hratchian, A. F. Izmaylov, J. Bloino, G.Zheng, J. L. Sonnenberg, M. Hada, M. Ehara, K. Toyota, R. Fukuda, J. Hasegawa, M. Ishida, T. Nakajima, Y. Honda, O. Kitao, H. Nakai, T. Vreven, J. A. Montgomery, Jr., J. E. Peralta, F. Ogliaro, M. Bearpark, J. J. Heyd,
E. Brothers, K. N. Kudin, V. N. Staroverov, T. Keith, R. Kobayashi, J. Normand, K. Raghavachari, A. Rendell, J. C. Burant, S. S. Iyengar, J. Tomasi, M. Cossi, N. Rega, J. M. Millam, M. Klene, J. E. Knox, J. B. Cross, V. Bakken, C. Adamo, J. Jaramillo, R. Gomperts, R. E. Stratmann, O. Yazyev, A. J. Austin, R. Cammi, C. Pomelli, J. W. Ochterski, R. L. Martin, K. Morokuma, V. G. Zakrzewski, G. A. Voth, P. Salvador, J. J. Dannenberg, S. Dapprich, A. D. Daniels, O. Farkas, J. B. Foresman, J. V. Ortiz, J. Cioslowski, and D. J. Fox, Gaussian, Inc., Wallingford CT, 2013.

50. P. J. K. a) H.-J. Werner, G. Knizia, F. R. Manby and M. Schütz, WIREs Comput Mol Sci 2, 242-253 (2012) and b) MOLPRO, version 2012.1, a package of ab initio programs, H.-J. Werner, P. J. Knowles, G. Knizia, F. R. Manby, M. Schütz, P. Celani, T. Korona, R. Lindh, A. Mitrushenkov, G. Rauhut, K. R. Shamasundar, T. B. Adler, R. D. Amos, A. Bernhardsson, A. Berning, D. L. Cooper, M. J. O. Deegan, A. J. Dobbyn, F. Eckert, E. Goll, C. Hampel, A. Hesselmann, G. Hetzer, T. Hrenar, G. Jansen, C. Köppl, Y. Liu, A. W. Lloyd, R. A. Mata, A. J. May, S. J. McNicholas, W. Meyer, M. E. Mura, A. Nicklass, D. P. O'Neill, P. Palmieri, D. Peng, K. Pflüger, R. Pitzer, M. Reiher, T. Shiozaki, H. Stoll, A. J. Stone, R. Tarroni, T. Thorsteinsson, and M. Wang, , see http://www.molpro.net. c) MOLPRO, version 2015.1, a package of ab initio programs, H.-J. Werner, P. J. Knowles, G. Knizia, F. R. Manby, M. Schütz, P. Celani, W. Györffy, D. Kats, T. Korona, R. Lindh, A. Mitrushenkov, G. Rauhut, K. R. Shamasundar, T. B. Adler, R. D. Amos, A. Bernhardsson, A. Berning, D. L. Cooper, M. J. O. Deegan, A. J. Dobbyn, F. Eckert, E. Goll, C. Hampel, A. Hesselmann, G. Hetzer, T. Hrenar, G. Jansen, C. Köppl, Y. Liu, A. W. Lloyd, R. A. Mata, A. J. May, S. J. McNicholas, W. Meyer, M. E. Mura, A. Nicklass, D. P. O'Neill, P. Palmieri, D. Peng, K. Pflüger, R. Pitzer, M. Reiher, T. Shiozaki, H. Stoll, A. J. Stone, R. Tarroni, T. Thorsteinsson, and M. Wang, , see http://www.molpro.net. .

51. P. C. Maria and J. F. Gal, The Journal of Physical Chemistry, 1985, 89, 1296-1304.

52. C. C. Alves, T. B. C. Campos and W. A. Alves, Spectrochimica Acta Part A: Molecular and Biomolecular Spectroscopy, 2012, 97, 1085-1088.

53. P. Hu, R. Zhang, X. Meng, H. Liu, C. Xu and Z. Liu, Inorg Chem, 2016, 55, 2374-2380.

54. J. Burt, W. Levason, M. E. Light and G. Reid, Dalton T, 2014, 43, 14600-14611.

55. C. J. Groenenboom, H. J. Hageman, T. Overeem and A. J. M. Weber, Makromol Chem, 1982, 183, 281-292.

56. J. P. Fouassier, P. Jacques, D. J. Lougnot and T. Pilot, Polym Photochem, 1984, 5, 57-76.

57. F. Morlet-Savary, X. Allonas, C. Dietlin, J. P. Malval and J. P. Fouassier, Journal of Photochemistry and Photobiology A: Chemistry, 2008, 197, 342-350.

58. X. Allonas, J. Lalevee, F. Morlet-Savary and J. P. Fouassier, Polimery-W, 2006, 51, 491-498.

59. H. Fischer, R. Baer, R. Hany, I. Verhoolen and M. Walbiner, J Chem Soc Perk T 2, 1990, 787-798.

60. L. Ding, L. Shen, X.-B. Chen and W.-H. Fang, The Journal of Organic Chemistry, 2009, 74, 8956-8962.

61. A. D. McNaught and A. Wilkinson, IUPAC. Compendium of Chemical Terminology, Blackwell Scientific Publications, Oxford, 2nd edn., 1997. 
62. C. M. Marian, Wiley Interdisciplinary Reviews: Computational Molecular Science, 2012, 2, 187-203.

63. J. Tatchen, N. Gilka and C. M. Marian, Phys Chem Chem Phys, 2007, 9, 5209-5221.

64. S. Perun, J. Tatchen and C. M. Marian, ChemPhysChem, 2008, 9, 282-292.

65. A. Toniolo and M. Persico, The Journal of Chemical Physics, 2001, 115, 1817-1827.

66. S. Salzmann, V. Martinez-Junza, B. Zorn, S. E. Braslavsky, M. Mansurova, C. M. Marian and W. Gärtner, The Journal of Physical Chemistry A, 2009, 113, 9365-9375.

67. J. P. Fouassier, D. Ruhlmann and A. Erddalane, Macromolecules, 1993, 26, 721-728.

68. H. Fischer and L. Radom, Angew Chem Int Edit, 2001, 40, 1340-1371.

69. M. G. Evans and M. Polanyi, T Faraday Soc, 1936, 32, 13331359.

70. R. P. Bell, Proceedings of the Royal Society of London A: Mathematical, Physical and Engineering Sciences, 1936, 154, 414-429.

71. C. Dietlin, X. Allonas, A. Defoin and J.-P. Fouassier, Photochemical \& Photobiological Sciences, 2008, 7, 558-565. 